\title{
Clinical Efficacy, Drug Safety, and Surrogate Endpoints
}

\section{Has Aducanumab Met All of Its Expectations?}

Linda A. Hershey, MD, PhD, and Rawan Tarawneh, MD

Neurology ${ }^{\circledR} 2021 ; 97: 517-518$. doi:10.1212/WNL.0000000000012453

We recently learned that aducanumab has been approved by the US Food and Drug Administration (FDA) for the treatment of Alzheimer disease. As neurologists, we need to carefully review the evidence from the phase $1 \mathrm{~B}$ and III randomized controlled clinical trials concerning the clinical efficacy and safety of this drug in symptomatic persons with mild cognitive impairment or mild dementia who have elevated cerebral levels of $\beta$-amyloid (A $\beta)$. We should also gain an appreciation for how this drug acquired accelerated approval from the FDA on the basis of the surrogate endpoint of $A \beta$ plaque reduction as measured by PET imaging. We owe this to our patients and to their caregivers.

In this issue of Neurology ${ }^{\circledR}$, Salloway and Cummings ${ }^{1}$ describe the Multiple Dose Study of Aducanumab (BIIB037) (Recombinant, Fully Human Anti-A $\beta$ IgG1 mAb) in Participants With Prodromal or Mild Alzheimer's Disease (PRIME) trial (phase 1B), in which monthly IV infusions of high-dose aducanumab showed definite reduction of $A \beta$ on amyloid PET imaging studies. In 2 identical phase 3 trials, Phase 3 Study of Aducanumab (BIIB037) in Early Alzheimer's Disease (EMERGE and ENGAGE), significant clinical benefit at 78 weeks was seen only in the high-dose group $(10 \mathrm{mg} / \mathrm{kg})$ of 1 of these trials (EMERGE). Consistent reduction of $A \beta$ on amyloid PET was observed in both of the phase 3 trials at 78 weeks.

As a counterviewpoint in this issue of Neurology, Knopman and Perlmutter ${ }^{2}$ argue that the clinical benefit of aducanumab seen in the EMERGE trial was small, amounting to 3 months' worth of delay in clinical decline. They also mention that when results from both phase 3 trials were combined, there were no significant clinical benefits for the high dose. To justify accelerated approval, the FDA relied on a surrogate endpoint, removal of $A \beta$ plaques on amyloid PET. The danger of relying on a surrogate endpoint such as $A \beta$ reduction is that the relationship between $A \beta$ reduction and cognitive improvement is unclear. Several trials with other amyloidreducing drugs have shown no cognitive benefit, and 1 recent trial actually showed some cognitive worsening ${ }^{2,3}$ On the other hand, biomarkers have had an important role in Alzheimer drug development because, compared to cognitive endpoints, they are less likely to be affected by the day-to-day variability produced by mood changes and sleep disturbances. ${ }^{4}$

When it comes to drug safety, Salloway and Cummings ${ }^{1}$ mention that the most common adverse effects of aducanumab in EMERGE and ENGAGE were those that have been commonly associated with other amyloid-lowering drugs: amyloid-related imaging abnormalities (ARIA) with either edema (ARIA-E) or hemorrhage (ARIA-H). ${ }^{5}$ In the EMERGE trial, 34\% of those in the high-dose group experienced ARIA, and in ENGAGE, it was 35.5\%. Knopman and Perlmutter ${ }^{2}$ point out that ARIA adverse events (edema or hemorrhage) were more likely to be seen in those who carried at least 1 APOE $\varepsilon 4$ allele, a finding that has been observed in previous trials of amyloid-lowering drugs. ${ }^{5}$ This means that safety monitoring with follow-up MRI scans needs to be integrated into the routine management of patients who are treated with aducanumab. ${ }^{2}$ The most common symptoms of ARIA-E include headache, confusion, dizziness, visual changes, falls, or nausea. One male patient enrolled in

\author{
Correspondence \\ Dr. Hershey \\ linda-hershey@ouhsc.edu
}

RELATED ARTICLES

Viewpoint

Aducanumab, Amyloid

Lowering, and Slowing of

Alzheimer Disease

Page 543

\section{Viewpoint}

Prescribing Aducanumab in the Face of Meager Efficacy and Real Risks

Page 545 
ENGAGE was a homozygous $A P O E$ \&4 allele carrier. He developed both ARIA-E and ARIA-H and reportedly experienced clinical symptoms of ARIA-E that lasted $\approx 6$ months after the drug was discontinued; nevertheless, signs of ARIAH persisted. ${ }^{6}$

In summary, before we prescribe aducanumab, we need to explain several things to our patients and their caregivers. First, this drug is intended for those who are in the mild cognitive impairment or mild dementia stage of Alzheimer disease; it was not tested in those with moderate or severe dementia (this is currently not mentioned on the product label). ${ }^{7}$ Second, verifying the presence of amyloid pathology in the brain with an amyloid PET scan is recommended because aducanumab is not intended for treating other types of dementia. ${ }^{8}$ Cost and availability of amyloid PET scans could be an issue for patients with limited resources and those who live in rural areas. Amyloid PET scans typically cost between $\$ 5,000$ and $\$ 7,000$ per study and are not reimbursed by third-party payers. ${ }^{8}$ Third, APOE $\varepsilon 4$ screening, baseline MRI, and follow-up MRI are all important for predicting the risk of ARIA adverse events (increased risk of ARIA with APOE $\varepsilon 4 / \varepsilon 4$ was not mentioned on the product label). ${ }^{7}$ Fourth, the price of aducanumab is considerable (wholesale acquisition costs are currently $\$ 4,312$ per monthly infusion for a $74-\mathrm{kg}$ patient at the $10-\mathrm{mg} / \mathrm{kg}$ dose). ${ }^{7}$ Fifth, no stopping rules are currently provided in the drug label, but the American Academy of Neurology recommended that an "outcomes-based payment arrangement" should be worked out in the future with third-party payers. ${ }^{8}$ Finally, patients and their caregivers need to understand that the clinical benefits of aducanumab are small and that more data will be needed in the future to determine whether these benefits are clinically or functionally meaningful to patients (a new clinical trial has been recommended by the FDA to Biogen to resolve these questions). ${ }^{7}$ We look forward to seeing these new data.

\section{Study Funding}

No targeted funding reported.

\section{Disclosure}

L. Hershey is an associate editor for Neurology. She receives honoraria from MedLink Corp for preparing annual updates. She serves on the Network of Experts Committee for the FDA. R. Tarawneh is an assistant editor for Neurology. She is funded by the National Institute of Aging (R21 AG06775501A1). Go to Neurology.org/N for full disclosures.

\section{References}

1. Salloway S, Cummings J. Aducanumab, amyloid lowering, and slowing of Alzheimer disease. Neurology. 2021;97(11):543-544.

2. Knopman DS, Perlmutter JS. Prescribing aducanumab in the face of meager efficacy and real risks. Neurology. 2021;97(11):545-547.

3. Panza F, Lozapone M, Logroscino G, Imbimbo BP. A critical appraisal of amyloid- $\beta$ targeting therapies for Alzheimer's disease. Nat Rev Neurol. 2019;15(2):73-88.

4. Fleming TR, Powers JH. Biomarkers and surrogate endpoints in clinical trials. Stat Med. 2012;31(25):2973-2984.

5. Sperling RA, Jack CR, Black SE, et al. Amyloid related imaging abnormalities (ARIA) in amyloid modifying therapeutic trials: recommendations from the Alzheimer's Association Research Roundtable Workgroup. Alzheimers Dement. 2011; 7(4):367-385

6. VandeVrede L, Gibbs DM, Koestler M, et al. Symptomatic amyloid-related imaging abnormalities in an APOE e4/e4 patient treated with aducanumab. Alzheimers Dement. 2020;12(1):e12101.

7. Federal Drug Administration. Accessed July 8, 2021. https://www.accessdata.fda. gov/drugsatfda_docs/label/2021/761178s000lbl.pdf.

8. American Academy of Neurology. Aducanumab Resources. Accessed July 8, 2021 https://www.aan.com/tools-and-resources/practicing-neurologists-administrators/ aducanumab-resources/. 


\section{Neurology}

\section{Clinical Efficacy, Drug Safety, and Surrogate Endpoints: Has Aducanumab Met All of Its Expectations?}

Linda A. Hershey and Rawan Tarawneh

Neurology 2021;97;517-518 Published Online before print July 7, 2021

DOI 10.1212/WNL.0000000000012453

\section{This information is current as of July 7, 2021}

\section{Updated Information \& Services}

References

Citations

Subspecialty Collections

Permissions \& Licensing

Reprints including high resolution figures, can be found at: http://n.neurology.org/content/97/11/517.full

This article cites 6 articles, 2 of which you can access for free at: http://n.neurology.org/content/97/11/517.full\#ref-list-1

This article has been cited by 1 HighWire-hosted articles: http://n.neurology.org/content/97/11/517.full\#\#otherarticles

This article, along with others on similar topics, appears in the following collection(s):

All Cognitive Disorders/Dementia

http://n.neurology.org/cgi/collection/all_cognitive_disorders_dementia Alzheimer's disease

http://n.neurology.org/cgi/collection/alzheimers_disease

MCI (mild cognitive impairment)

http://n.neurology.org/cgi/collection/mci_mild_cognitive_impairment

Information about reproducing this article in parts (figures,tables) or in its entirety can be found online at:

http://www.neurology.org/about/about_the_journal\#permissions

Information about ordering reprints can be found online:

http://n.neurology.org/subscribers/advertise

Neurology ${ }^{\circledR}$ is the official journal of the American Academy of Neurology. Published continuously since 1951, it is now a weekly with 48 issues per year. Copyright (C 2021 American Academy of Neurology. All rights reserved. Print ISSN: 0028-3878. Online ISSN: 1526-632X.

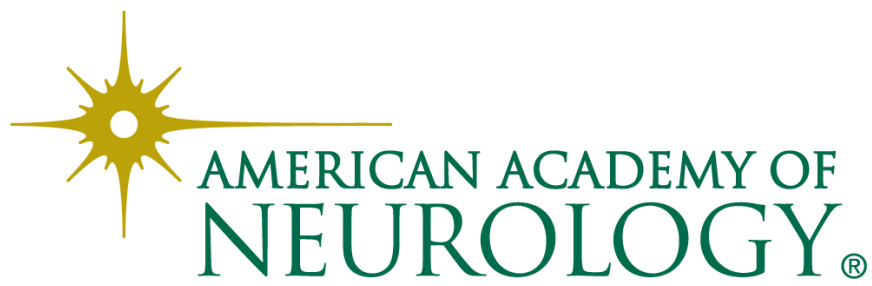

